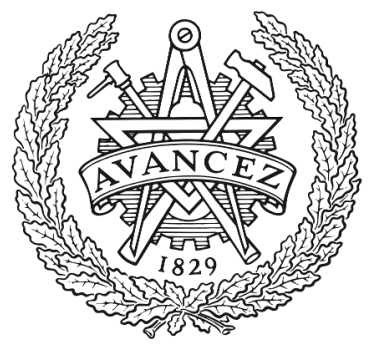

CHALMERS

UNIVERSITY OF TECHNOLOGY

\title{
Clustering and assemblage building
}

Downloaded from: https://research.chalmers.se, 2023-04-26 11:54 UTC

Citation for the original published paper (version of record):

Palmer, H., Righard, E., Björling, N. et al (2020). Clustering and assemblage building. Comparative Urban Research from Theory to Practice: Co-production For sustainablity: 89-112.

http://dx.doi.org/10.2307/j.ctv10tq4cj.11

N.B. When citing this work, cite the original published paper. 
Chapter Title: Clustering and assemblage building Chapter Author(s): Henrietta Palmer, Erica Righard, Nils Björling, Eva Maria Jernsand, Helena Kraff and Lillian Omondi

Book Title: Comparative Urban Research From Theory To Practice

Book Subtitle: Co-Production For Sustainability

Book Editor(s): DAVID SIMON, HENRIETTA PALMER, JAN RIISE

Published by: Bristol University Press, Policy Press. (2020)

Stable URL: https://www.jstor.org/stable/j.ctv10tq4cj.11

JSTOR is a not-for-profit service that helps scholars, researchers, and students discover, use, and build upon a wide range of content in a trusted digital archive. We use information technology and tools to increase productivity and facilitate new forms of scholarship. For more information about JSTOR, please contact support@jstor.org.

Your use of the JSTOR archive indicates your acceptance of the Terms \& Conditions of Use, available at https://about.jstor.org/terms

This book is licensed under a Creative Commons Attribution-NonCommercial 4.0 International License (CC BY-NC 4.0). To view a copy of this license, visit https://creativecommons.org/licenses/by-nc/4.0/. 


\section{FIVE}

\section{Clustering and assemblage building}

Henrietta Palmer, Erica Righard and Nils Björling, with Eva Maria Jernsand, Helena Kraff and Lillian Omondi

'As if entering into a shared space from different doors - but without a floor to walk upon.'

Workshop meeting, Cape Town, 2018

\section{Introduction}

Everyone with an interest in the urban will consciously or unconsciously compare earlier experiences of other urban environments with what is experienced at hand; they will be 'thinking (cities) through elsewhere' (Robinson, 2015: 195). It is therefore difficult to imagine any other situation where such comparative activities play out more distinctively than in urban situations induced by migration and other forms of mobility. Who is ever better set to do urban comparison than migrants constantly reminded of places left behind and trying to make sense of places of arrival? Therefore, migration is ultimately connected to comparative urbanism in what Jacobs calls 'an everyday comparison' (Jacobs, 2012: 910). 
This chapter describes comparative knowledge production by way of bringing together already existing research financed by other means and local development projects within a defined area of research and intervention. The projects were all dealing with migration but based in different urban contexts, and they were brought together in a systematic way we call clustering. This methodology was developed through a joint venture of comparative knowledge production involving researchers, practitioners and civil society actors at the Local Interactive Platforms (LIPs) in Gothenburg (GOLIP), Skåne (SKLIP) and Kisumu (KLIP). Based within the Mistra Urban Futures agenda for comparative research and its understanding of coproduced transdisciplinary research (as discussed in Chapters One and Two), this was a natural starting point. The project originally stemmed from a need to better understand international migration, and in particular refugee reception and integration, as this developed in Gothenburg and Malmö following the so-called refugee crisis in 2015. It was later reframed to include the situation of rural-urban migration in Kisumu and research at the intersection of inclusive tourism, urban multiculturalism and sustainable development in, among other places, Malmö, Gothenburg and Kisumu. As the work proceeded, it became clear that, at the urban level, migration and its consequences have similarities across varying societal contexts and that learning exchanges are valid.

Clustering represents a method for comparison and knowledge production across discrete research and development projects within a joint field or theme, but based in dissimilar societal contexts. Inspired by assemblage theory, as originally conceptualised by Gilles Deleuze and Felix Guattari (1987) and later developed and brought into the field of design and design thinking by Manuel DeLanda (2006), relevant key questions were identified to guide the comparative work. This approach enabled participants to exchange and discuss experiences, build new knowledges and elaborate potentials across projects and localities without full understanding of the 
often very different background, context and dynamic of each project. The contribution of the chapter lies primarily in its presentation of a methodology for knowledge exchange and building in a transdisciplinary and translocal setting, without a budget to fund a rigorous and systematic comparison on the empirical level.

The chapter first describes how this work proceeded over time; it outlines how the comparative method of clustering evolved from the first initiative to the consolidated framework resulting from the working process. The second section elaborates on clustering as a comparative method in a more general way, including positioning it in relevant theoretical debates. It then critically revisits the method of clustering, its benefits and challenges, and describes how some of the challenges were overcome. The final section of the chapter discusses how clustering as a comparative method can contribute to the overall aim of Mistra Urban Futures, namely that of Realising Just Cities.

\section{Setting the scene: a chronology}

The implementation of this comparative project was shaped by how it came about and the conditions under which it worked. We argue that our method is a case of clustering, but in fact it resembles much of a what we often think of as a research network, that is a gathering of researchers working on a common theme, but often from different disciplinary perspectives, universities or countries, for instance, usually with a limited budget for running costs related to network meetings but not research activities per se. The reason why we insist on this not being just a research network is the more systematic method derived from design theory we applied in our comparative work and which, we argue, contributed added value to each of the projects involved. This section describes how the clustering developed over time as new partners were involved in a stepwise manner, and how the comparative themes, discussed as 'entry 
points' in the section on theorising clustering, were identified in conjunction with this.

\section{Defining the theme: migration and urban development}

The comparative project was broadly entitled Migration and Urban Development and was set to focus on urban and regional development in relation to migration, including persons of varying migration backgrounds, legal statuses and citizenship. Through the opportunity to conduct comparative studies across Mistra Urban Futures' LIPs, the aim was to identify and understand the challenges and opportunities that migration presents in relation to sustainable urban development. Migration in the different urban settings involved various forms of migration, and a theoretical approach was developed for the comparative research that merged internal migration, primarily related to urbanisation processes, with international migration into a common framework. As international and internal migration are often separated by disciplinary boundaries, namely those of migration studies and urban studies, with this propositional project came an opportunity to contribute to a research direction integrating the two into one.

The project aimed at developing a multifaceted body of research for the consolidation and expansion of this integrated approach to migration and urban development, to further contribute as a compelling pilot for Mistra Urban Futures' strategic planning beyond 2020. It also set out to build knowledge alliances among academics, civil servants and civil society actors, enabling them to be well informed about each other's respective fields of knowledge, expertise and experiences, thus providing a grounding for future collaborations within this field of knowledge building.

Since the project inauguration by the Gothenburg and Skåne platforms in early 2017, the project has gone through different stages, formats of knowledge production, and actors' constellations and engagement. Openness and inclusiveness 
were conscious approaches to avoid getting stuck in the national or local perspectives preconceived by the initiators, but rather to be influenced by new project partners. However, as discussed later in this chapter, this 'openness' also involved disruptions of the working process; hence, a balance of openness and closedness is needed when staging this kind of inquiry. Within the approach, the concept of clustering became relevant, as the aligning projects were quite different from one another and not immediately comparable across local or national contexts. As a methodology, clustering was initially vague and did not offer any immediate guidance. Hence, to explore clustering as a methodology and to understand its potential for comparative knowledge building became a meta-goal of this project, beyond the objectives of the individual projects.

As this short chronology shows, the project itself emerged through different concerns and was shaped through the ongoing conceptualisation of clustering. It also shows how the method of clustering was fleshed out to become more instructive for the comparative research.

\section{The initial step: commonalities of international and internal migration}

A first scanning of interest in the field took place in Gothenburg in 2017 among around 30 practitioners from the public and civil sector from Malmö and Gothenburg, together with researchers from the Chalmers University of Technology, University of Gothenburg and Malmö University. The discussion was organised along three sub-themes. For the continued work at GOLIP, these themes remained productive; they were merged into one, forming the basis of the first GOLIP-funded research project related to migration. ${ }^{1}$

As the first initiative was taken by two Swedish LIPs, the research on migration and urban development was not initially engaged in a cross-national comparison. A first international meeting for a possible comparative project was staged at the Mistra Urban Futures annual conference in Kisumu 
in November 2017. It was decided then to not promote the themes that had framed the project up to this point, as they were biased towards the Swedish aftermaths of the comparatively large influx of asylum seekers from Syria and other wartorn countries in late 2015, and not necessarily relevant to the LIPs in other countries. Taking into consideration the varying situations of migration in the different urban contexts, project proposals were invited from other Mistra Urban Futures LIPs to enter into the comparative inquiry of migration and urban development. The workshop in Kisumu engaged participants interested in intersections of urban and migration issues that could form comparative approaches relevant to all platforms. The most important result was the notion of translocality, which allowed for understandings of both international migration and internal rural-to-urban migration, and hence resonated for all participants and their different experiences and research interests. This conceptual definition also became the first stepping stone for further development of the comparative methodological strategy.

\section{Consolidation: four transformative themes}

A second international workshop, in early 2018 in Malmö, involved ongoing research and development initiatives (not only research and development interests this time) related to migration and urban development. The initiatives had their base within the Mistra Urban Futures LIPs or existed in the 'vicinity' of the platforms. Fourteen participants, from both academia and practice, presented their ongoing research in six separate projects. The workshop was dominated by participants from the Gothenburg and Malmö platforms, with only one researcher and one practitioner from outside Sweden, namely Kisumu. A researcher from the University of Sheffield was connected via Skype.

The workshop was organised into a series of short presentations of the different research and development initiatives. In the 
discussions and reflections on the presentations, and what migration meant to each project constellation, four crosscutting and 'transformative' themes were identified: territories, practices, collaborations and languages. These themes were cross-cutting in the sense that they had relevance across all platforms and projects. What happened at this meeting was a first consolidation of comparative knowledge building as a joint enterprise. Even though some of the individual projects later decided to opt out from this comparative work, mainly due to lack of time and financial resources, the group started to develop innovative research directions and to plan for joint outputs. What previously had been merely a common interest in the topic of migration and urban development now served to engage the participants in joint project activities, which, among other things, resulted in a successful research bid in mid-2018 for a large project entitled Tourism in Multicultural Societies, including researchers from the universities in Gothenburg, Malmö and Kisumu. It can be argued that, at this point, the comparative project developed from being merely a topicbased network, to become an 'alliance of committedness' to both the content of comparative work and to the method of doing this work. A key reason for this to develop, we argue, was the emergence of the cross-cutting themes that created a sense of co-ownership in terms of a joint framework, which in turn generated new perspectives within the individual research projects. Hence, clustering was developed into a two-fold methodology, first, as a knowledge alliance across disciplinary and organisational boundaries, asking for a particular structure, protocols, documentation and practice, and, second, as content-oriented comparative work driven by defined transformative themes.

\section{Advancement: process as outcome}

Beyond a number of less formal meetings taking place between some of the individual participants whenever an opportunity 
emerged, the next prepared workshop was planned in conjunction with the Mistra Urban Futures annual conference in Cape Town in November 2018. The meeting was staged as an inquiry into the research and local development projects involved, assisted by the now defined method of comparison. The challenges and risks of working through a knowledge alliance were considered, with new participants from practice and academia joining in for the first time. With early results from the four transformative themes, the researchers and practitioners were able to reflect on and debate whether or not these had been productive in their individual projects.

With input from design-based research, a suggestion for a conceptualisation of clustering was made to understand clustering through assemblage theory, and the concept of 'composition'. In her taxonomy of urban comparison, Jennifer Robinson suggests composing comparisons as a distinguishable mood of comparing, as 'design[ing] bespoke projects grounded in shared features' (2015: 196) rather than in a comparison of similarities or differences. This compositional approach resembles that of assemblage. Although not everyone in the group was familiar with assemblage theory or such an approach, it was a stimulating argument that made everyone curious enough to want to explore it further. Against this background, initiators could discern how to create a comparative narrative of a number of discrete research projects (at this point four projects), coming from different contexts and based in varying epistemological assumptions. The sensation of overview also relaxed some of the anxieties and doubts regarding whether it was worthwhile engaging in a knowledge alliance of this kind. It is essential to raise these concerns, since allocated time and funding do set out important preconditions for collaborative and co-produced engagements, and indeed individual participants were grappling with the inadequacy of these. But, importantly, in our experience, clarity in the process design, a common understanding and the emergence of new perspectives can, 


\section{CLUSTERING AND ASSEMBLAGE BUILDING}

at least partly, substitute for this lack. This was pointed out by the participants who were supportive of further consolidation and of the method development.

In the following knowledge alliance session, in Gothenburg in March 2019, work continued determinedly on deepening the transformative themes, and participants were asked to present their work from an inquiry into these themes. At this point, five projects were involved. Three had been involved from the initial phase, while two joined subsequently. In addition to the two research projects already mentioned, one addressed the organisation of labour market integration from the perspective of a non-governmental organisation (GOLIP), one was about housing, language training, and labour market integration among asylum seekers and newly arrived refugees (SKLIP), and one concerned the structure and role of social networks of rural migrants arriving in urban areas (KLIP). A main issue raised in the workshop concerned to what extent the four themes were guiding the analytical work and knowledge production in the individual projects, and to what extent they were addressing how the transdisciplinary co-production that each project was engaged with separately was accomplished. Clearly, co-produced transdisciplinary research is central to the ethos of Mistra Urban Futures and the preconditions for such research approaches, as discussed in Chapter Two. Of relevance here is that the knowledge alliances at hand bore features that resonated with our themes, namely the crossing of boundaries, including boundaries of territories, practices and languages. In this double-sighted view, the themes enabled us to discuss the transformative themes as, on the one hand, determining the characteristic of the knowledge alliance itself, and, on the other hand, as analytical lenses for the comparative knowledge production. The conclusion reached was that it is relevant to consider both the 'what' and the 'how' of the transdisciplinary and comparative co-production of knowledge. From a detailed examination of the project presentations, comments were organised to address 
the various forms of 'what' and 'how', and their performative outcomes. These two distinctions speak to the transformative properties of the themes, describing them both in terms of a process of transformation and as the outcomes of such.

Besides these emerging definitions, two important findings and conclusions advanced our method. The first one was to eliminate the theme of transformative collaboration, as this could be collapsed into transformative practices, thus avoiding confusion with the overall collaborative research approach of transdisciplinary co-production. The second one was that in combining process and outcomes, the 'how' and 'what' of the analytical work, each thematic lens became redefined through these combined properties. The transformative territories, as identified in the Kisumu workshop, would now be described as 'translocality', the transformative practices as 'trans-sectionality', and the transformative language as 'translanguage' (see the next section). With these new findings, clustering as a productive method had the potential to reach beyond mere network capacities. While this sequential development was dependent on an embedded dynamic and was unintentional, we shall now revisit it with a systematic and more theoretical gaze.

\section{Theorising clustering}

Clustering, as applied in this comparative project, is given a double meaning and form. The first form is clustering of project participants into a knowledge alliance, and the second is a clustering of substantive projects as a composition or an assemblage building. The assemblage building was initially structured by four, later reduced to three, transformative themes. These became our entry points into a common construction of extracts from our different references and experiences. The assemblage building was thereby composed around a set of key questions/themes, rather than being defined by a set of cases. Here we outline and discuss what 
knowledge alliance, assemblage building and entry points as methodological concepts carry in terms of practical and critical imaginative capacities.

\section{Knowledge alliances}

The clustering of project participants into knowledge alliances diverged from collaborative settings where differences or similarities of selected cases are compared by teams across different contexts. It also differed from network meetings focused on specific thematic fields, which mainly aim at gathering knowledge and expertise to an available and accessible setting. By contrast, in this particular project, being transdisciplinary and comparative, the participants came from both academia and practice, hence not only bearing with them different knowledges, but also mandates, forms of legitimacy and capacities for interaction, which also clearly set different preconditions compared with most research networks. Andreas Novy and colleagues (2014: 433) define knowledge alliances as partnerships in which members ' ... share, produce and diffuse knowledge and build bridges between fragmented entities .... This was very evident in our case and, from our experience, knowledge alliances gain from a common thematic structure beyond the topic of research, and by a collective mindedness to develop a particular field of inquiry. In doing so, a certain frequency of meetings is required, as well as a certain consistency of group participants in order to not get stuck in the mode of continuous repetition or starting over when concepts are tested and reflected on as they are being developed. Moreover, protocols are needed for the introduction of new persons when a participant cannot participate any longer due to changed circumstances. Documentation of the working process is essential, also for the knowledge alliance to develop beyond the designated meetings. These descriptions and reflections should be shared continually to generate experiences of productive situations and a readiness for the comparative work when it is 
about to take place. This documentation also spurs iterations beyond the main process, as participants through the reflective work find reasons to engage with each other in other, albeit related, areas and contexts.

In part, this approach diverges from transdisciplinary coproduction as elaborated by Mistra Urban Futures. One divergence is found at the moment of inauguration. In this view, the project members should preferably define the problem jointly and invite participants who can contribute and add further knowledge that expands the kind of knowledge already existent within the group. Contrastingly, in this case, the knowledge alliance was initiated by a small group without a specific problem definition and came to assemble a number of projects related to a broader field of inquiry instead of a specified research problem. However, the openness of the process, the expansion of the project group, the iterations and the reflexivity share properties with a process of transdisciplinary co-production.

\section{Assemblage building}

The critique of 'best practices' has relevance here, as it can function to position comparative urbanism as part of a developmentalism agenda (Robinson, 2011). A replication and copying of practices from one context to another, with the ambition to solve a problem, could 'push past the target', as problems, albeit general in their impact, are often situated and solutions therefore have situated properties as well. Following on this, while learning from one context to another is inherent to any comparative endeavour, unconsciously replicating solutions that work in one context to another should be avoided, and this is central to the comparative ethos of Mistra Urban Futures (see Chapter Two). This understanding also emerged from the discussions, and reinforced the usefulness of the concept of assemblage building. Through an assemblage, we see projects as related, not individually but 


\section{CLUSTERING AND ASSEMBLAGE BUILDING}

to the larger composition. This makes it possible to start a comparison around available information of a specific theme rather than with the full contextual knowledge of each one of the different research projects or case studies. Hence, we can discuss, transfer and develop knowledge between the projects (based in different territories, sectors and languages) without fully understanding the nuances, often embedded in the varying backgrounds, situations and disciplines that have informed and shaped the development of each one.

Colin McFarlane (2011) has identified three strands of thinking and forming of assemblage in urban theory: as a descriptive focus through which explanations emerge from a thick description; as a way to rethink agency, particularly in relation to socio-material interaction; and as critical imaginary through the composition as such. In our case, the last strand resonates well: themes emerged as a critical response to how territories, practices and languages have impact on the integration of (internal and international) migrants in different ways across different urban contexts. One could further use design thinking, whereas design-based research often uses assemblage building as a method (DeLanda, 2006; Björling, 2016), that is, trying out multiple constellations of different parts for the opening-up of new imaginaries. A comparison in this manner is then the result of both the potential of included knowledge, references and experiences and their internal and external relations (Deleuze and Guattari, 1987). Through the selection of themes and key questions, assemblage theory becomes potentially useful. At the same time as the assemblage establishes a dynamic starting point for comparison, it emphasises continual rearrangement of components and processes and thereby also has the capacity to combine ongoing transformations and changing conditions within the different contexts. According to Manuel DeLanda (2006), the productive capacity of the assemblage depends on the interplay between its individual parts of knowledge and the co-productive capacity of the whole. To understand the engaged projects as an assemblage form or composition gives a freedom 
also to ask new questions from the content and designed format of the assemblage. A process of interplay takes place as the assemblage in turn is transformed and reveals a common start for development of the knowledge of the group. McFarlane (2011) points out that due to the adaptability embedded in the properties of an assemblage, one might avoid using the potential of conflicts and contradictions between parts, but rather find 'lines of flight' that name the possibility of creating something new. We decided to call our emerging lines of flight entry points and designated the three remaining themes identified, namely transformative territories, transformative practices and transformative languages, as entry points for clustering of knowledge and practices.

\section{Entry points}

To contextualise this discussion, we provide a short backtracing of the definitions of the original four themes, which were set as an outcome of the Malmö workshop.

'Transformative territories' implies a re-territorialisation of integration. Within this theme, territories are regarded as productive in terms of creating conditions for integration and further urban development, as well as products themselves of social practices related to migration and integration. 'Transformative practices' implies that alternative and/or organically developed practices could contribute to inclusion at a local level, but also be transformed by societal processes of inclusion. 'Transformative collaborations' implies that new types of collaboration are needed to address the challenges and harvest the opportunities that arise in cities' reception of international and internal migrants. It implies collaboration across sectors, silos and cities, as well as the transformation of different roles with respect to migration and urban development. 'Transformative languages' implies that language has a performative role and reflects on which language is used and how it is used when addressing migration in relation to urban development. 


\section{CLUSTERING AND ASSEMBLAGE BUILDING}

The last Gothenburg workshop was designated as an interrogation of these definitions. What had been the relevance of these themes for the ongoing research until this point in time? What suggestions for additional readings could be made? The propositional definition of the themes as transformative indicates a two-pathway production in each of them. This feature was clarified, meaning that the transformative capacity was described as both a process and a performative outcome. As a result of these interrogations, the four themes were redefined as three, partly since collaboration resonates in two distinct ways - in both the empirical analysis and the transdisciplinary research process as such, that is, in both the 'what' and the 'how', as discussed earlier. In addition, many of the workshop participants agreed that the empirical findings of collaborative transformations were closely connected to findings of the transformative practices. The identification of a number of empirical examples of the three remaining themes in each research project enabled critical reflection on these themes across the projects. This enabled a fruitful way of building knowledge that was place-specific and, at the same time, informed by insights from other contexts.

One further evolution regards how the entry points, through their readings, cross projects, and how, through their double productive properties, they can be redefined. The transformative territories, as had already been addressed in the Kisumu workshop, were now framed as translocality. ${ }^{2}$ The transformative practice was redefined as trans-sectionality, and the transformative language as trans-language. These three concepts all share the notion of crossing different kinds of boundaries and of having plural and relational belongings. The first one is known and deployed in geography, anthropology and migration studies, pointing towards the situated nature of transnational networks (see, for example, Brickell and Datta, 2011) and emerging as a research field in its own right (Greiner and Sakdapolrak, 2013). The concept of transsectionality has evolved lately as a proposition to provide the 
framework of intersectionality with a fluidity in the definitions of identities. As intersectionality proposes a layered number of identities within each person, trans-sectionality suggests that these identities are never permanent but can change and be reconstituted (Nicole, 2014). In our case, this speaks more to (professional) 'roles' than 'identities', as we discussed them in terms of transcending different mandates in relation to practices engaged in processes of urban inclusion.

Trans-language stems from pedagogy and implies not insisting on one language only in a pedagogical situation, but allowing and stimulating the use of more languages, often the national majority language (see, for example, Canagarajah, 2011), but here it also regards languages of varying professions and academic disciplines (see also Nikulina et al, 2019). While transformative language was introduced as a theme to reflect critically on how language takes a performative role in processes of migration and urban development, the concept of translanguage opens an uncertainty that can undermine pre-set definitions in a productive way.

In the context of comparative urban discourses, Jane M. Jacobs has pointed out that finding methods that are sensitive to 'trans', such as translocal, transurban and translation, can give us important keys to the objects of comparative urbanism. She suggests that it can be exactly the transformative processes of cities that create commonalities between them. Jacobs states that as anthropology has provided us with the notion of multi-sited ethnographies through which to understand the production of global effects, it has also:

'given rise in geography to thinking through networks and assemblages, and ... for thinking beyond models of the diffusion of stable objects (policies, models of architectural form) to more open concepts of translation and transduction, in which there is a constant remaking of the world through reiterative practices.' (Jacobs, 2012: 908) 
This is a compelling remark that speaks to the definition of our overall project at the intersection of urbanism and migration. At this intersection, clustering as a comparative typology has evoked three trans-concepts, which are both critical and imaginative, and possibly productive for the making of just cities.

\section{Benefits and challenges}

The learning outcomes of this project relate to the content of the comparative work, and to the conceptualisation of the comparative method. It is a shared understanding among the participants that clustering and how it evolved, both in terms of a knowledge alliance and as the building of a project assemblage, provided fruitful learning to each of the individual research projects. However, since all research projects are still ongoing, the particular impact on each individual research project is still too early to delineate. Learning outcomes relating to the comparative methodology and its conceptualisation are more distinguishable at this point. The challenges and benefits of collaborative work are well examined in the literature on participatory practices. Many of these are similar to the challenges and benefits of clustering as a process. Here we therefore do not linger on outcomes such as mutual learning and network effects (Wiek et al, 2014), but rather address other benefits and challenges possibly significant for clustering as co-produced transdisciplinary research.

\section{Process design and group consolidation}

From our experience, knowledge alliances and the method of assemblage cannot be too elusive. Someone must both lead the project and the design of the project as such. In parallel, it was acknowledged that some kind of project consolidation or institutionalisation must take place to create a certain degree of stability. Otherwise the project is trapped in a very unstable format. This institutionalisation, we argue, happens through 
the repetition of meetings in which participation initially is a 'soft commitment' but eventually becomes 'harder', as well as through the development of a shared understanding of the joint endeavour and its design. As time is precious for everyone involved, the design of the project has to be put in place in a transparent manner by someone who can dedicate both time and reflexive work to the project institutionalisation, as it is not realistic to expect this to happen fully in the common meetings.

For the implementation of clustering as a comparative methodology, at least in our case, it is important to stress the setting. This comparative endeavour was embedded within a long-term collaboration between LIPs within Mistra Urban Futures. This setting enabled an iterative process between, on the one hand, the development of individual projects, and on the other, a series of joint workshops, seminars and conferences, which would probably be much more challenging in other, more temporary, settings.

Another lesson learned is that although it has been essential for this project to be agile and responsive, which works well for both the knowledge alliance and for the substantive assemblage, one also needs to define the extent to which flexibility is productive. When is the time to close the group to new project members and stop elaborating on project definition and goals? When is it time to define the entry points to which comparison can be made? Consolidating too early brings the risk of excluding potentially fruitful collaborations and imaginaries, while doing so too late might actually prevent consolidation and lead to members leaving the project. There is no clear recipe for how this should happen. From our experience, this balance is contestable and delicate and needs to be discussed openly.

\section{Uncertainty and the role of a narrative}

As already described, clustering as a process is difficult to control. It depends on possible funding, possible co-engagements 
beyond what is set by the knowledge alliance, and the possible establishment of new projects. Together this implies that time planning and results are difficult to foresee. Even pre-set meetings can be postponed, as the collaboration is constantly looking for the fulfilment of short-term objectives, and when these are not within sight, the immediate relevance of knowledge alliance activities declines. Comparative projects with a devoted budget typically have a fixed project plan with expected outcomes. But when there is no budget, participants, processes and outcomes tend to be continually renegotiated and ever-changing. In the absence of a fixed plan, continual documentation of each developmental stage of the project becomes essential for the process to institutionalise. This is an effect of the set-up, and experiences from various 'commoning' processes witness similar urgency (Stavrides, 2016; Džokić and Neelen, 2018). Documentation needs to take on a reflective and narrative role, not only to give access to the process, design and the shared language for established projects participants as well as potential new ones, but also to set the agenda in terms of suggesting structuring concepts regulating and shaping the process forward. One such narrative is the realising of just cities. The following and final section briefly comments on how this comparative project possibly has the potential to contribute a narrative to the overall achievement of Mistra Urban Futures' comparative work.

\section{Contribution to realising just cities}

Mistra Urban Futures' aim is realising just cities. To raise the question of how a limited endeavour like this comparative project contributes to this overarching aim is, of course, as ambitious as it is necessary. Here we reflect on how, from our experiences, this comparative project has taken some small steps towards contributing to learning about migration and urban development as well as how the methodology of clustering can be further applied and possibly contribute to urban justice. 


\section{Clustering as a method for cross-city learning in globalised societies}

Clustering, as developed in this comparative project, offers a method for comparison and learning across discrete projects and, in several ways, fundamentally different urban contexts. It can be implemented without large funding, but relies on existing and funded research and development projects. The defined entry points enabled exchanges and knowledge production across territorial, practice and language boundaries while remaining context-sensitive. The outcome is, on the one hand, a shared set of concepts, as described earlier, which as 'lines of flight' can be brought back to individual research projects where new theory and practice can be outlined. Through this comparative method, the knowledge production is localised, as outcomes from the comparative work are inserted back into the projects. In line with Jennifer Robinson's questions about whether we can 'promote theory cultures which are alert to their own locatedness ... and committed to the revisability of theoretical ideas' (2016: 188), this is an important point to embrace. Moreover, in this way, the approach of clustering not only takes a critical stance on 'best practices', but also offers a way forward and beyond such approaches.

While we estimate that clustering has proved a fruitful method to address comparative urban research, obviously funding for comparative work is crucial to extract a metanarrative from a number of discrete research projects. As funding has only been available for a discursive level, much of the comparative research within this project still remains to be done. However, we consider the methodological advance made to be an important research contribution in itself and suggest it as a response to Jennifer Robinson's call for an experimental comparative urbanism across the imagination of a global North-South division (Robinson, 2011). 


\section{Ways forward}

In her work on urban justice, Susan Fainstein (2013) examines three urban contexts in a comparative inquiry. Her definition of urban justice, with references to democracy, diversity and equity, responds to Nancy Fraser's definitions of justice as representation, recognition and redistribution (or participation, identities and material distribution) (Fraser, 1996, 2000). The three concepts bearing the prefix 'trans' and developed in this comparative project - translocality, trans-sectionality and trans-language - can be considered in the light of Fainstein's and Frasers's discussions. The prefix 'trans' responds to a liminal condition of being both in between different territories, roles/identities and languages, and towards, as in a process of transformation, where the outcome of such a process is not set. Here, we want to advocate an opening in discussions about realising just cities; the three concepts could function to raise new propositions for planning from pre-set and fixed positions of citizens to an acceptance of in-between positions, including, for instance, positions of belonging to multiple territories, fluid roles and agencies, and the conscious use of multiple languages as performative actions. Such a future framework calls for a reconceptualisation of what it is to belong, and how justice and just cities should be conceptualised in translocal settings.

\section{Acknowledgements}

This comparative project is based on the collaboration of civil servants and researchers from Mistra Urban Futures' local interactive platforms in Gothenburg, Kisumu and Malmö (GOLIP, KLIP and SKLIP). As writers of this chapter, we thank all the participants who have, at different stages, contributed to the development of this work: Maher Akob, Ester Barinaga, Emma Björner, Kristina Grange, Hanna Hellgren, Sanna Isemo, Maria 
Hellström Reimer, Helene Holmström, Sandra Lundberg, Jennie Ström, Steven Sule, Caroline Wanjiku Kihato, Maria José Zapata Campos and Klara Öberg.

The comparative project builds on the following research projects: Organizing Integration, WP 3, based at the University of Gothenburg and funded by the Swedish Research Council for Health, Working Life and Welfare, together with GOLIP/ Mistra Urban Futures in 2017-20; Migrant Networks and Leverage, based at Maseno University and funded by KLIP/ Mistra Urban Futures, 2018-19; Governance and the Local Integration of Migrants and Europe's Refugees, based at Malmö University and funded through ERA-NET Sustainable Urban Futures under the European Union Research and Innovation Programme Horizon 2020, with funding for the Swedish part from the Swedish Research Council for Sustainable Development, Formas, in 2017-20; The Uneven Geography of Migration, based at Chalmers University of Technology and funded by GOLIP/Mistra Urban Futures in 2018-19; and Turismens roll i multikulturella samhällen (Tourism in Multicultural Societies), based at Malmö University and funded by Formas from 2019-22.

\section{Notes}

1 The Uneven Geography of Migration is a research project comparing how a law about housing for newly arrived refugees, effective as of 1 March 2016, affected the recipience of migrants in three municipalities in western Sweden. Details of this and the other projects on which this comparative endeavour is based, appear in the acknowledgements on pp 109-10. The concept of translocality was also central in the keynote lecture by Caroline Wanjiku Kihato at the Mistra Urban Futures annual conference 2017. See https://youtu.be/6s78-axCINk 


\section{CLUSTERING AND ASSEMBLAGE BUILDING}

\section{References}

Björling, N. (2016) 'Sköra stadslandskap: planeringsmetoder för att hantera urbaniseringens rumsliga inlåsningar' (Fragile urban landscapes: planning methods to open spatial lock-ins of urbanization), Doctoral thesis, Gothenburg: Chalmers University of Technology.

Brickell, K. and Datta, A. (eds) (2011) Translocal Geographies: Spaces, Places, and Connections, Farnham: Ashgate.

Canagarajah, S. (2011) 'Translanguaging in the classroom: emerging issues for research and pedagogy', Applied Linguistics Review, 2(1): 1-28.

DeLanda, M. (2006) A New Philosophy of Society: Assemblage Theory and Social Complexity, New York, NY: Continuum International Publishing Group.

Deleuze, G. and Guattari, F. (1987) A Thousand Plateaus: Capitalism and Schiozophrenia, Minneapolis, MN: University of Minnesota Press.

Džokić, A. and Neelen, M. (2018) Upscaling, Training, Commoning: Constructing a Future That is Yet to be, Berlin: Jovis.

Fainstein, S. (2013) 'The just city', International Journal of Urban Sciences, 18(1): 1-18. doi: 10.1080/ 12265934.2013.834643

Fraser, N. (1996) 'Social justice in the age of identity politics: redistribution, recognition and participation', Tanner Lectures on Human Values, Stanford University, 30 April -2 May, 1996.

Fraser, N. (2000) 'Rethinking recognition', New Left Review, MayJune, 2000(3): 107-20.

Greiner, C. and Sakdapolrak, P. (2013) 'Translocality: concepts, applications and emerging research perspectives', Geography Compass, 7/5: 373-84. doi:10.1111/gec3.12048

Jacobs, J.M. (2012) 'Commentary: comparing comparative urbanisms’, Urban Geography, 33(6): 904-914. doi: 10.2747/ 0272-3638.33.6.904

McFarlane, C. (2011) 'Assemblage and critical urbanism', City, 15(2): 204-24. doi: 10.1080/13604813.2011.568715 
Nicole, K. (2014) 'Trans-forming identities: integrating intersectionality and trans-sectionality', iintrospectivescience [Blog]. Available from: https://iintrospectivescience.wordpress.com/2014/04/01/ trans-forming-identities-integrating-intersectionality-and-transsectionality [Accessed 23 September 2019].

Nikulina, V., Lindal, J.L., Baumann, H., Simon, D. and Ny, H. (2019) 'Lost in translation: a framework for analysing complexity of coproduction settings in relation to epistemic communities, linguistic diversities and culture', Futures, 113: 102442. doi: 10.1016/ j.futures.2019.102442

Novy, A., Habersack, S. and Schaller, B. (2014) 'Innovative forms of knowledge production: transdisciplinarity and knowledge alliance', in F. Moulaert, D. MacCallum, A. Mehmood and A. Hamdouch (eds) The International Handbook on Social Innovation, Cheltenham and North Hampton, MA: Edward Elgar, p. 433.

Robinson, J. (2011) 'Cities in a world of cities: the comparative gesture', International Journal of Urban and Regional Research, 35(1): 1-23. doi:10.1111/j.1468-2427.2010.00982.x

Robinson, J. (2016) 'Comparative urbanism: new geographies and cultures of theorizing the urban', International Journal of Urban and Regional Research, 40(1): 187-99. doi:10.1111/1468-2427.12273

Stavrides, S. (2016) Common Space: City as Commons, London: Zed Books.

Wiek, A., Talwar S., O'Shea M. and Robinson J. (2014) 'Toward a methodological scheme for capturing societal effects of participatory sustainability research', Research Evaluation, 23(2): $117-32$. 